\title{
Transverse Response of an Axially Moving Beam with Intermediate Viscoelastic Support
}

\author{
Sajid Ali (D), ${ }^{1}$ Sikandar Khan $\left(\mathbb{D},{ }^{2}\right.$ Arshad Jamal $\left(\mathbb{D},{ }^{3}\right.$ Mamon M. Horoub ${ }^{(D)}{ }^{4}$ \\ Mudassir Iqbal $\mathbb{D},,^{5,6}$ and Kennedy C. Onyelowe $\mathbb{D}^{7,8}$ \\ ${ }^{1}$ Mechanical and Energy Engineering Department, Imam Abdulrahman Bin Faisal University, Dammam 31441, Saudi Arabia \\ ${ }^{2}$ Department of Mechanical Engineering, King Fahd University of Petroleum and Minerals, Dhahran 31261, Saudi Arabia \\ ${ }^{3}$ Interdisciplinary Research Center of Smart Mobility and Logistics (IRC-SML), King Fahd University of Petroleum and Minerals, \\ Dhahran 31261, Saudi Arabia \\ ${ }^{4}$ Department of Mechanical and Mechatronics Engineering, Birzeit University, Birzeit, State of Palestine \\ ${ }^{5}$ Shanghai Key Laboratory for Digital Maintenance of Buildings and Infrastructure, State Key Laboratory of Ocean Engineering, \\ School of Naval Architecture, Ocean and Civil Engineering, Shanghai Jiao Tong University, Shanghai 200240, China \\ ${ }^{6}$ Department of Civil Engineering, University of Engineering and Technology, Peshawar, Pakistan \\ ${ }^{7}$ Department of Civil Engineering, Michael Okpara University of Agriculture, Umudike, Nigeria \\ ${ }^{8}$ Department of Civil and Mechanical Engineering, Kampala International University, Kampala, Uganda
}

Correspondence should be addressed to Kennedy C. Onyelowe; kennedychibuzor@kiu.ac.ug

Received 2 July 2021; Revised 2 October 2021; Accepted 15 October 2021; Published 18 November 2021

Academic Editor: Agathoklis Giaralis

Copyright $(2021$ Sajid Ali et al. This is an open access article distributed under the Creative Commons Attribution License, which permits unrestricted use, distribution, and reproduction in any medium, provided the original work is properly cited.

This study presented the transverse vibration of an axially moving beam with an intermediate nonlinear viscoelastic foundation. Hamilton's principle was used to derive the nonlinear equations of motion. The finite difference and state-space methods transform the partial differential equations into a system of coupled first-order regular differential equations. The numerical modeling procedures are utilized for evaluating the effects of parameters, such as axial translation velocity, flexure rigidities of the beam, damping, and stiffness of the support on the transverse response amplitude and frequencies. It is observed that the dimensionless fundamental frequency and magnitude of axial speed had an inverse correlation. Furthermore, increasing the flexure rigidity of the beam reduced the transverse displacement, but at the same instant, fundamental frequency rises. Vibration amplitude is found to be significantly reduced with higher damping of support. It is also observed that an increase in the foundation damping leads to lower fundamental frequencies, whereas increasing the foundation stiffness results in higher frequencies.

\section{Introduction}

Axially moving beams have numerous applications in various branches of engineering, such as manufacturing, civil, mechanical, chemical, and aerospace engineering [1-4]. Typical applications explored in previous studies include conveyor belts, medical nanorobots, power saw, band saw, and magnetic tape [5-9]. At the nano/micron level, the motion of the substrate is significant, and small fluctuations can result in a low-quality product [10-13]. Transverse vibrations triggered by external disturbances during a particular process may be lowered by providing end supports beneath the moving beam in the form of rotating rolls [14]. Though end supports are beneficial, they are not sufficient to stabilize the motion of moving substrate. End support controller was used to stabilize the transverse vibration of an axially moving Kirchhoff beam [15]. Additional intermediate support in the moving span is often required [16]. Intermediate support between the rolls offers superior web processing quality in comparison to the traditional end support. Vibration of an axially moving beam with an intermediate foundation has become a burning research topic 
since the last decade. Several studies have attempted to analyze axially moving beams with elastic foundations. Dynamic analysis of coupled moving beams through a Winkler elastic support was investigated by Gaith and Müftü [17]. Yang et al. [18] studied the free vibration of axially moving elastic beams resting on an elastic foundation. In their study, they utilized the Galerkin method to discretize the equation of motion. Fundamental frequencies of transverse fluctuations in a moving beam were studied by utilizing different numerical methods [19]. Liu et al. [20] explored the dynamics and instability of the Euler-Bernoulli beam as a function of several variables such as axially moving speed, position, and weight of the lumped mass. The study results revealed that any increase in lumped mass is inversely associated with resulting systems' fundamental frequencies. Dynamics of axially moving beam attached with energy sink and a piezoelectric device was studied in [21, 22]. A significant effect of the attachment on the response was observed. Norouzi and Younesian [23] investigated the chaotic behavior of an axially moving beam supported by a stiff foundation. Cosine-cosine function was used to obtain the approximate solution of the equation of motion. Chaos indication was obtained by setting Lyapunov exponent as a criterion. Mohammadzadeh and Mosayebi [24] investigated the vibration in rail supports and joints by considering it as an axially moving beam resting on an elastic foundation. The effect of rail support and joints in the locality of a bridge in railway track was investigated.

Kural and Ozkaya [25] investigated the performance of a microbeam fluid-carrying media by utilizing the modified couple stress theory. In another study, Yan et al. [26] employed the theoretical model to examine the stability and dynamics of a thin cantilever beam. The beam was attached with a moving station submerged in a fluid. Calim [27] explored the patterns of free and forced fluctuation in a functionally graded beam assembly supported with an intermediate elastic foundation. Tang et al. [28] explored the transverse vibration of an axially accelerating beam having time-dependent axial tension. Analysis revealed that variation in axial speed and axial tension has a direct influence on the resonance. Mirzabeigy and Madoliat [29] studied the large amplitude-free vibration of beams resting on the supporting foundation. The Winkler model and Euler-Bernoulli method were used to study the induced vibrations in elastic foundation and beam, respectively. Ghannadiasl [30] proposed the application of dynamic Green function (DGF) to investigate the dynamic response of railways under varying loading conditions. The load was varying in nature with different speeds and accelerations. Variation in moving load, as well as the elastic parameters of the foundation, was investigated. It was shown by the modeling results that the maximum deflection depends on the increasing or decreasing acceleration of the moving load.

Similarly, Zhang et al. [31] utilized the complex modal analysis to investigate the dynamic response of a moving beam resting on intermediate support. Ding et al. [32] investigated the axially moving beam traveling with supercritical speed. The impact of rotary inertia and shear deformation on the transverse fluctuations was investigated.
Zhao et al. [33] analytically investigated an axially moving microbeam. Coupled thermoelastic vibration and heat transfer process was presented. Mohamed et al. [34] presented a novel numerical procedure to forecast the forced steady-state and nonlinear free response of curved beam under clamped-clamped boundary conditions. An and Su [35] presented the generalized integral transform technique as a numerical approach for the dynamic analysis of Timoshenko beam. Esen [36] considered functionally graded Timoshenko beam to investigate the dynamic response using the modified finite element method (FEM). The beam under consideration was resting on elastic support and was exposed to a mass moving with a variable speed. For the first time, Ding et al. [37] proposed a generalized boundary conditions approach for axially moving beams supported by vertical and torsional springs at both ends. Shao et al. [38] investigated the nonlinear dynamic behavior of a moving membrane with fluctuating speed. It was concluded that the nonlinear vibration characteristics of a membrane are sensitive to the initial motion conditions.

A thorough review of the literature reveals a significant lack of comprehensive investigations on the problem of an axially moving beam with nonlinear viscoelastic intermediate support. To the best of author's knowledge, problem of transverse vibration in an axially moving beam is tackled by providing supports at the ends of the moving beam. In authors' opinion, end supports are likely to result in lower quality process. Therefore, intermediate viscoelastic supports are presented here as a possible solution to mitigate the vibration in moving beams. Also, in view of the nature of involved equations of motion, authors also feel the need to investigate the application of the finite difference method (FDM) on the nonlinear dynamics of beams under consideration. In this study, transverse vibrations in axially traveling beams with a roll-to-roll configuration supported by the viscoelastic intermediate foundation were studied. Nonlinear equations of motion for transverse vibrations were derived using Hamilton's principle. A model based on the finite difference method coupled with the state-space approach was presented. The effect of parameters, such as axial translation velocity, flexure rigidities of the beam, damping, and stiffness of the support on the transverse response amplitude and frequencies of the system in the subcritical region, were investigated.

\section{Problem Formulation}

An axially moving beam on a viscoelastic foundation for analyzing the vibrations characteristics is presented in Figure 1. This model mainly includes stiffness, damping, length, and end supports. The beam has flexural rigidity EI and axial tension $\mathrm{T}$ and moves with an axial velocity $(v)$. Transverse displacement of the beam is $w(x, t)$.

Free body diagram of an infinitesimal element of the considered beam is shown in Figure 2. Here, $S$ is the shear force and $M_{b}$ is the bending moment. Viscous damping force, spring force, and inertial force are represented by $F_{d}$, $F_{s}$, and $F_{I}$, respectively. First, the total kinetic energy and potential energy of the moving beam were calculated by 


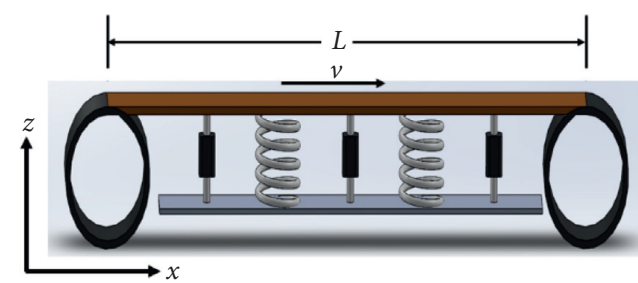

FIGURE 1: Schematic of an axially moving beam with intermediate support.

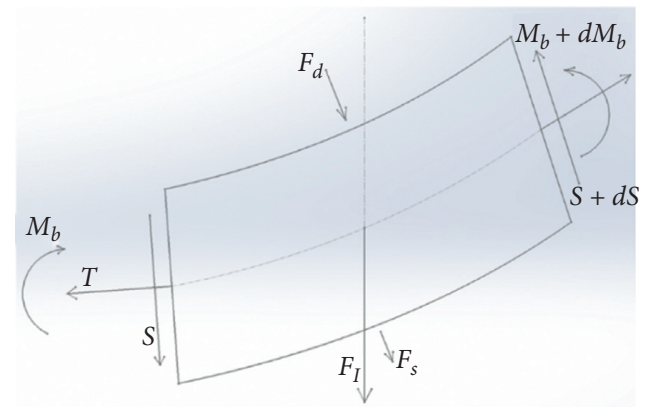

FIGURE 2: Free body diagram of the infinitesimal beam element.

considering $\rho$ as the density and A as the cross-sectional area of the beam. Hamilton's principle was then applied to derive the equation of motion. Transverse vibration of the beam is described by

$$
\rho A\left[\frac{\partial^{2} w}{\partial t^{2}}+2 v \frac{\partial^{2} w}{\partial t \partial x}+\frac{\partial v}{\partial t} \frac{\partial w}{\partial x}+v^{2} \frac{\partial^{2} w}{\partial x^{2}}\right]-\left[T \frac{\partial^{2} w}{\partial x^{2}}+E I \frac{\partial^{4} w}{\partial x^{4}}\right]+k_{1} w+k_{2} w^{3}++\xi\left[\frac{\partial w}{\partial t}+v \frac{\partial w}{\partial x}\right]=0
$$

where $E$ is the modulus off elasticity, $\rho$ is the density of the beam material, $A$ is the cross-sectional area, and $I$ is the moment inertia of the beam. Axial speed and axial tension in the beam are represented by $v$ and $T$, respectively. The linear stiffness, nonlinear stiffness, and damping of the foundation are represented by $k_{1}, k_{2}$, and $\xi$, respectively. Introducing the following dimensionless variables transforms the equation of motion into a normalized equation:

$$
\begin{aligned}
x_{*} & =\frac{x}{L}, \\
w_{*} & =\frac{w}{L}, \\
t_{*} & =t \sqrt{\frac{T}{\rho A L^{2}}}, \\
v_{*} & =v \sqrt{\frac{\rho A}{T}}, \\
\alpha & =\frac{E I}{T L^{2}}, \\
k_{1 *} & =\sqrt{\frac{k L}{T}},
\end{aligned}
$$

$$
\begin{aligned}
& k_{2 *}= \sqrt{\frac{k L^{3}}{T A}}, \\
& \xi_{*}= \xi \sqrt{\frac{L}{\rho A T}}, \\
& \frac{\partial^{2} w_{*}}{\partial t_{*}^{2}}+2 v_{*} \frac{\partial^{2} w_{*}}{\partial t_{*} \partial x_{*}}+\left(v_{*}^{2}-1\right) \frac{\partial^{2} w_{*}}{\partial x_{*}^{2}}+v_{*} \frac{\partial w_{*}}{\partial x_{*}}+\alpha \frac{\partial^{4} w_{*}}{\partial x_{*}^{4}} \\
& \quad+k_{1^{*}}^{2} w_{*}+k_{2^{*}}^{2} w_{*}^{3}+\xi_{*}\left(\frac{\partial w_{*}}{\partial t_{*}}+v_{*} \frac{\partial w_{*}}{\partial x_{*}}\right)=0,
\end{aligned}
$$

where $v_{*}$ represents the dimensionless transport speed (a ratio between physical and wave velocity in the beam), while parameter $\alpha$ is the dimensionless flexural rigidity.

2.1. Finite Difference Formulation. Transverse vibrations of the moving beam on a nonlinear viscoelastic foundation are numerically solved, and essential mathematical formulation is presented in equation (2). An analysis approach based on the finite difference method is used to obtain second-order ordinary differential equations (ODEs) by transforming the fourthorder HPDE. Discretization of the equation is then achieved by the central difference scheme given by the following equations: 


$$
\begin{aligned}
&\left.\frac{\partial w_{*}}{\partial x_{*}}\right|_{x_{* i}}=\frac{w_{*(i+1)}-w_{*(i-1)}}{2 * d x_{*}}, \\
&\left.\frac{\partial^{2} w_{*}}{\partial x_{*}^{2}}\right|_{x_{* i}}=\frac{w_{*(i+1)}-2 * w_{* i}+w_{*(i-1)}}{d x_{*}^{2}}, \\
&\left.\frac{\partial^{4} w_{*}}{\partial x_{*}^{4}}\right|_{x_{* i}}=\frac{w_{*(i+2)}-4 * w_{*(i+1)}+6 * w_{* i}-4 * w_{*(i-1)}+w_{*(i-2)}}{d x_{*}^{4}} .
\end{aligned}
$$

The following second-order ordinary differential equations are produced:

$$
\begin{aligned}
& \frac{d^{2} w_{* 1}}{d t_{*}^{0}}+\frac{v}{d x_{*}} \frac{d w_{* 2}}{d t_{*}}+\frac{\left(v_{*}^{2}-1\right)}{d x_{*}^{2}}\left(-2 * w_{* 1}+w_{* 2}\right)+\frac{v_{*}}{2 * d x_{*}} * w_{* 2}+\cdots \\
& \cdots \frac{\alpha}{d x_{*}^{4}}\left(6 * w_{* 1}-4 * w_{* 2}+w_{* 3}\right)+k_{1 *}^{2} w_{* 1}+k_{1 *}^{2} w_{* 1}^{3}+\xi_{*} \frac{d w_{* 1}}{d t_{*}}+\frac{\xi_{*} v_{*}}{2 * d x_{*}} * w_{* 2}=0 \\
& \frac{d^{2} w_{* 2}}{d t_{*}^{2}}+\frac{v_{*}}{d x_{*}}\left(-\frac{d w_{* 1}}{d t_{*}}+\frac{d w_{* 3}}{d t_{*}}\right)+\frac{\left(v_{*}^{2}-1\right)}{d x_{*}^{2}}\left(w_{* 1}-2 * w_{* 2}+w_{* 3}\right)+\frac{\dot{v_{*}}}{2 * d x_{*}}\left(-w_{* 1}+w_{* 3}\right)+\cdots \\
& \cdots+\frac{\alpha}{d x_{*}^{4}}\left(-4 * w_{* 1}+6 * w_{* 2}-4 * w_{* 3}+w_{* 4}\right)+k_{1 *}^{2} w_{* 2}+k_{2 *}^{2} w_{* 2}^{3}+\cdots \\
& \cdots+\xi_{*} \frac{d w_{* 2}}{d t_{*}}+\frac{\xi_{*} v_{*}}{2 * d x_{*}} *\left(-w_{* 1}+w_{* 3}\right)=0 \\
& \vdots \\
& \vdots \\
& \vdots \\
& \vdots \\
& \vdots \\
& \frac{d^{2} w_{*(n-1)}}{d t_{*}^{2}}+\frac{v_{*}}{d x_{*}} \frac{d w_{*(n-2)}}{d t_{*}}+\frac{\left(v_{*}^{2}-1\right)}{d x_{*}^{2}}\left(w_{*(n-2)}-2 * w_{*(n-1)}\right)+\frac{\dot{v_{*}}}{2 * d x_{*}} * w_{*(n-2)}+\cdots \\
& \cdots+\frac{\alpha}{d x_{*}^{4}}\left(w_{*(n-3)}-4 * w_{*(n-2)}+6 * w_{*(n-1)}\right)+k_{1 *}^{2} w_{*(n-1)}+k_{2 *}^{2} w_{*(n-1)}^{3}+\cdots \\
& \ldots \xi_{*} \frac{d w_{*(n-1)}}{d t_{*}}+\frac{\xi_{*} v_{*}}{2 * d x_{*}} * w_{*(n-2)}=0
\end{aligned}
$$


where the total number of spatial points is represented by $n$ and step size is represented by $\mathrm{d} x_{*}$. The subsequent matrix form of equation (6) is given by

$$
M \frac{d^{2} w_{*}}{d t_{*}^{2}}+\left[2 v_{*} G+\xi_{*} M\right] \frac{d w_{*}}{d t_{*}}+\left[\left(v_{*}^{2}-1\right) K_{1}+v_{*} * G+\alpha K_{2}+\xi_{*} v_{*} G+k_{1^{*}}^{2} M\right] w_{*}+k_{2^{*}}^{2} M w_{*}^{3}=0
$$

where $\mathrm{M}, \mathrm{G}, K_{1}$, and $K_{2}$ are $(n-1) *(n-1)$ matrices, which have the following structure:

$$
\begin{aligned}
& M=\left[\begin{array}{ccccc}
1 & 0 & 0 & \ldots & 0 \\
0 & 1 & 0 & 0 & \vdots \\
0 & 0 & \ddots & \ddots & 0 \\
\vdots & 0 & \ddots & 1 & 0 \\
0 & \ldots & 0 & 0 & 1
\end{array}\right], \\
& G=\frac{1}{2 * d x_{*}}\left[\begin{array}{ccccc}
0 & 1 & 0 & \ldots & 0 \\
-1 & 0 & 1 & 0 & \vdots \\
0 & -1 & \ddots & \ddots & 0 \\
\vdots & 0 & \ddots & \ddots & 1 \\
0 & \ldots & 0 & -1 & 0
\end{array}\right] \\
& K_{1}=\frac{1}{d x_{*}^{2}}\left[\begin{array}{ccccc}
-2 & 1 & 0 & \ldots & 0 \\
-1 & -2 & 1 & 0 & \vdots \\
0 & -1 & \ddots & \ddots & 0 \\
\vdots & 0 & \ddots & \ddots & 1 \\
0 & \ldots & 0 & -1 & -2
\end{array}\right] \\
& K_{2}=\frac{1}{d x_{*}^{4}}\left[\begin{array}{ccccccccc}
6 & -4 & 1 & 0 & \ldots & \cdots & \cdots & \cdots & 0 \\
-4 & 6 & -4 & 1 & 0 & \ldots & \ldots & \cdots & 0 \\
1 & -4 & 6 & -4 & 1 & 0 & \ldots & \cdots & 0 \\
0 & 1 & -4 & 6 & -4 & 1 & 0 & \cdots & 0 \\
\vdots & 0 & \ddots & \ddots & \ddots & \ddots & \ddots & \ddots & 0 \\
\vdots & \vdots & \ddots & \ddots & \ddots & \ddots & \ddots & \ddots & 0 \\
\vdots & \vdots & \vdots & \ddots & 1 & -4 & 6 & -4 & 1 \\
\vdots & \vdots & \vdots & \vdots & \ddots & 1 & -4 & 6 & -4 \\
0 & \ldots & \ldots & \ldots & \ldots & 0 & 1 & -4 & 6
\end{array}\right] .
\end{aligned}
$$

System of second-order ordinary differential equations was then transformed into a system of first-order ordinary differential equations by applying state-space approach: 


$$
\begin{aligned}
& \frac{d y_{1}}{d t_{*}}=y_{2} \\
& \frac{d y_{2}}{d t_{*}}=\frac{d^{2} w_{* 1}}{d t_{*}^{2}}=-\frac{v_{*}}{d x_{*}} y_{4}+\frac{\left(v_{*}^{2}-1\right)}{d x_{*}^{2}}\left(2 * y_{1}-y_{3}\right)-\frac{\dot{v}}{2 * d x_{*}} * y_{4}+\cdots \\
& \cdots+\frac{\alpha}{d x_{*}^{4}}\left(-6 * y_{1}+4 * y_{3}-y_{5}\right)-k_{1 *}^{2} y_{1}-k_{2}^{2} y_{1}^{3}-\xi_{*} * y_{2}-\frac{\xi_{*} v_{*}}{2 * d x_{*}} * y_{4}+f \\
& \frac{d y_{3}}{d t_{*}}=y_{4} \\
& \frac{d y_{4}}{d t_{*}}=\frac{d^{2} w_{* 2}}{d t_{*}^{2}}=-\frac{v_{*}}{d x_{*}}\left(y_{2}-y_{6}\right)+\frac{\left(v_{*}^{2}-1\right)}{d x_{*}^{2}}\left(-y_{1}+2 * y_{3}-y_{5}\right)-\frac{v_{*}}{2 * d x_{*}}\left(y_{2}-y_{6}\right)-\cdots \\
& \cdots-\frac{\dot{v}}{2 * d x_{*}} *\left(y_{2}-y_{6}\right)+\frac{\alpha}{d x_{*}^{4}}\left(4 * y_{1}-6 * y_{3}+4 * y_{5}-y_{7}\right)-\cdots \\
& \cdots-k_{1 *}^{2} * y_{3}-k_{2 *}^{2} y_{3}^{3}-\xi_{*} * y_{4}-\frac{\xi_{*} v_{*}}{2 * d x_{*}} *\left(y_{2}-y_{6}\right)+f \\
& \vdots \\
& \vdots \\
& \vdots \\
& \vdots \\
& \vdots \\
& \vdots \\
& \frac{d y_{2 *(n-1)-1}}{d t_{*}}=y_{2 *(n-1)} \\
& \frac{d y_{2 *(n-1)}}{d t_{*}}=-\frac{v_{*}}{d x_{*}} y_{2 *(n-1)-2}+\frac{\left(v_{*}^{2}-1\right)}{d x_{*}^{2}}\left(-y_{2 *(n-1)-3}+2 * y_{2 *(n-1)-1}\right)-\frac{v_{*}}{2 * d x_{*}} y_{2 *(n-1)-2}-\cdots \\
& \cdots-\frac{v_{*}}{2 * d x_{*}} * y_{2 *(n-1)-2}+\frac{\alpha}{d x_{*}^{4}}\left(-y_{2 *(n-1)-5}+4 * y_{2 *(n-1)-3}-6 * y_{2 *(n-1)-1}\right)-\cdots \\
& \cdots-k_{1 *}^{2} y_{2 *(n-1)-1}-k_{2 *}^{2} * y_{2 *(n-1)-1}^{3}-\xi_{*} * y_{2 *(n-1)}-\frac{\xi_{*} v_{*}}{2 * d x_{*}} * y_{2(n-1)-2}+f
\end{aligned}
$$


where

$$
w_{* 1}=y_{1}, w_{* 2}=y_{3}, w_{* 3}=y_{5}, \ldots \ldots \ldots, w_{*(n-1)}=y_{2 *(n-1)-1} .
$$

The initial conditions used in the system of ODE's (8) are

$$
y_{1}(0)=y_{3}(0)=y_{5}(0)=\cdots=y_{2^{*}(n-1)-1}(0)=a\left(x_{*}\right) \text {, }
$$

$$
y_{2}(0)=y_{4}(0)=y_{4}(0)=\cdots=y_{2^{*}(n-1)}(0)=b\left(x_{*}\right)
$$

where $a\left(x_{*}\right)$ is the initial transverse deflection and $b\left(x_{*}\right)$ represents the initial transverse speed.

\section{Numerical Illustrations and Discussion}

Numerical simulations were performed to investigate the effect of different factors such as flexural rigidity of the beam, axial speed of the beam, damping of the foundation, and stiffness of the foundation on the vibration characteristics of the axially traveling beam. Values of the parameters used in the simulations are given in Table 1. Simulations were performed for the initial transverse displacement of " $a\left(x_{*}\right)=0.01 \sin \left(x_{*}\right)$ " and initial transverse speed condition of " $b\left(x_{*}\right)=0$ ". An in-house matlab code was used for the simulations.

First of all, the solution method used in the current analysis (Method 1) was verified by comparing it with the method (Method 2) presented by $\mathrm{An}$ and Su [35]. Comparison of the midspan transverse displacement for the case of an axially moving beam having nondimensional speed of “ $v_{*}=0.1$ " and nondimensional flexure rigidity of " $\alpha=0.2$ " is shown in Figure 3.

Response obtained from both solution methods was found to be in good agreement. It was also observed that the solution method used in this study is an efficient approach having long-term stability and excellent convergence.

Figures 4 and 5 show the comparison of transverse vibration as a function of axial speed in an axially moving beam. Transverse displacement at different locations $\left(x_{*}=0.3,0.5\right.$, and 0.7$)$ of the beam at different axial speeds, $v_{*}=0.1,0.3$, and 0.5 , (equals to $3 \mathrm{~m} / \mathrm{s}, 9 \mathrm{~m} / \mathrm{s}$, and $15 \mathrm{~m} / \mathrm{s}$, respectively) is presented in Figure 4. Figure 5 plots the trend of the fundamental frequency at different axial speeds. It may be noted from Figure 5 that an increased value of axial speed is accompanied by an exponential decrease in dimensionless fundamental frequency. For the stationary beam, it has a positive value of 7.3, which ultimately reaches zero for an axial speed approaching a value of 1.18 (equals to $35 \mathrm{~m} / \mathrm{s}$ ). The critical speed of the beam can also be interpreted as the speed at which the frequency of the vibration becomes zero; therefore, the critical speed of an axially moving beam under the abovementioned conditions is $35 \mathrm{~m} / \mathrm{s}$. Although the fundamental frequency of the vibration is experiencing a downward trend, the amplitude of vibration is
TABLE 1: Values of parameters used in simulations.

\begin{tabular}{lcc}
\hline S. No. & Parameters & Value \\
\hline 1 & Length of the beam $(L)$ & $1 \mathrm{~m}$ \\
2 & Density $(\rho)$ & $2710 \mathrm{~kg} / \mathrm{m}^{3}$ \\
3 & Axial tension $(T)$ & $2.5 \mathrm{kN}$ \\
4 & Width of the beam & $0.1 \mathrm{~m}$ \\
5 & Thickness of the beam & $0.01 \mathrm{~m}$ \\
6 & Modulus of elasticity $(E)$ & $6.9^{*} 10^{10} \mathrm{~Pa}$ \\
7 & Axial speed of the beam $(v)$ & $3 \mathrm{~m} / \mathrm{s}$ \\
8 & Foundation stiffness (linear, $\left.k_{1}\right)$ & $800 \mathrm{~N} / \mathrm{m}$ \\
9 & Foundation stiffness (non-linear, $\left.k_{2}\right)$ & $200 \mathrm{~N} / \mathrm{m}$ \\
10 & Foundation damping $(\xi)$ & $4 \mathrm{Ns} / \mathrm{m}^{2}$ \\
\hline
\end{tabular}

unaffected, as evident from Figure 4. Therefore, it is concluded that the critical speed at flexure rigidity of " 0.2 " is 1.18. Similarly, Figures 6 and 7 show the impact of flexure rigidity on the transverse fluctuations of moving beams resting on the viscoelastic foundation.

Figure 6 shows the effect of flexural rigidity, $\alpha$, on the midspan transverse displacement of axially moving beam. Based on Figure 6, increasing the flexure rigidity of the beam reduces the transverse displacement $(24 \%$ decrease in displacement magnitude by increasing $\alpha$ from 0.2 to 0.3 , and $47 \%$ decrease in magnitude by increasing $\alpha$ from 0.3 to 0.5 ) but at the same time will increase the nondimensional fundamental frequency from 7.3 to 9.8, as shown in Figure 7. Flexure rigidity also increases the critical speed of the axially moving beam (from 1.18 to 1.65). The higher value of flexure rigidity will somehow increase the internal damping (in terms of lower vibration amplitude) but at the cost of higher fundamental frequency.

Figures 8 and 9 represent the effect of damping of viscoelastic support on the vibration of the beam. Transverse displacement of beam at different locations $\left(x_{*}=0.3,0.5\right.$, and 0.5$)$ for different values of the damping factor is given in Figure 9. A sharp decline in the response is observed throughout the beam length with an increase in the damping of the viscoelastic support.

Transverse displacement of midpoint $\left(x_{*}=0.5\right)$ of the beam is plotted for different axial speeds $\left(v_{*}=0.1,0.3\right.$, and 0.5$)$ at increasing values of damping factor $\left(\xi_{*}=0.005,2.0\right.$, and 3.5) (Figure 9). As shown in Figure 9, with an increase in damping of the support, there is a quite visible reduction in the vibration amplitude. Interestingly, the vibration amplitude reduction is more visible when beam is moving with higher axial speed. A rapid reduction in the vibration magnitude for the case of $\xi_{*}=3.5$ is observed when the axial speed is $v_{*}=0.5$.

The effect of the support damping on the nondimensional fundamental frequency of the beam is presented in Figure 10. Nondimensional frequency and the critical speed of the beam decrease with an increase in the damping. Nondimensional frequency decreases from 7.3 to 6.4 , and critical speed decreases from 1.18 to 1.15 when the damping is increased from 0.05 to 3.5 .

Figure 11 presents the variation of nondimensional fundamental frequency as a function of nondimensional axial speed at various magnitudes of support stiffness. An 


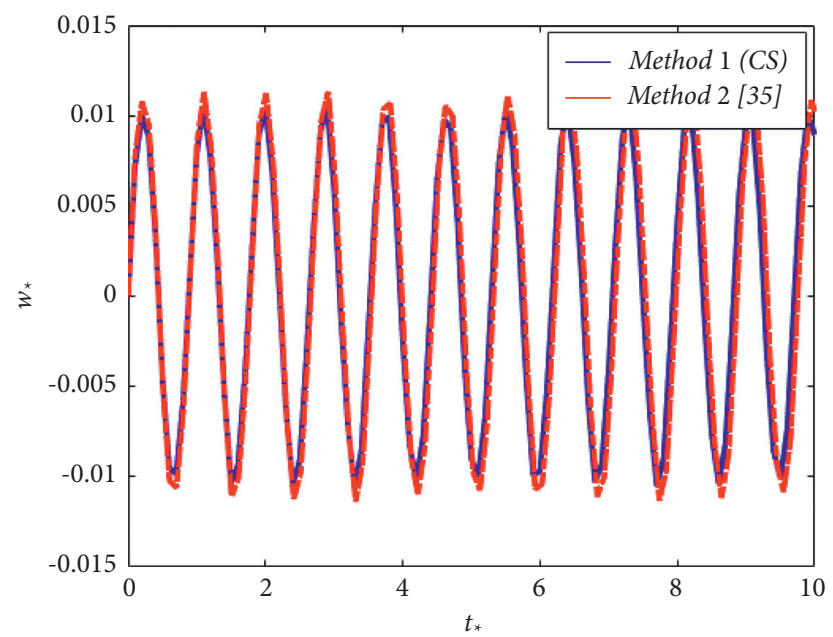

Figure 3: Transverse displacement comparison (current solution and solution from [35]).
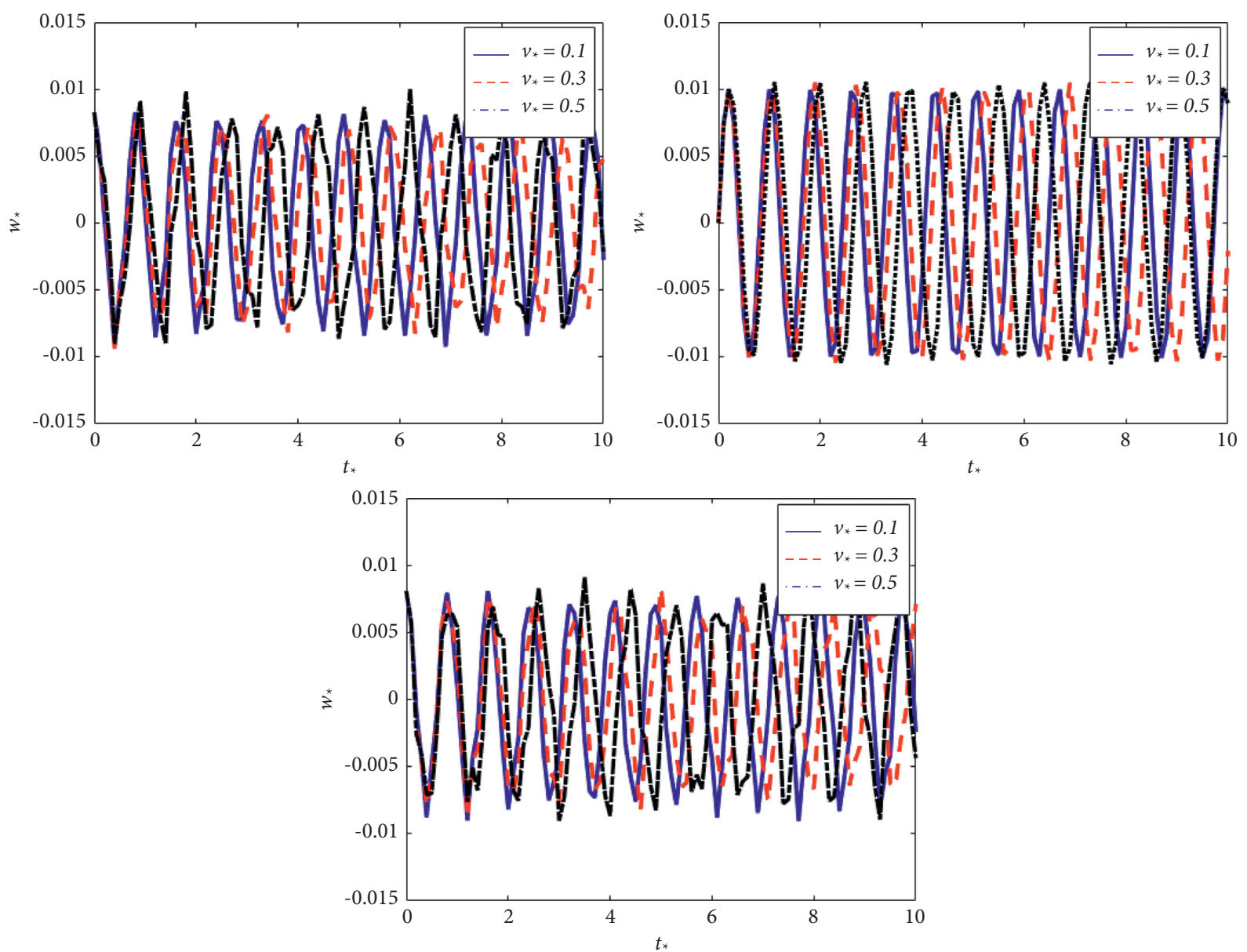

Figure 4: Transverse displacement comparison at different values of axial speed, (a) $x_{*}=0.3$ and $\alpha=0.2$, (b) $x_{*}=0.5$ and $\alpha=0.2$, and (c) $x_{*}=0.7$ and $\alpha=0.2$. 


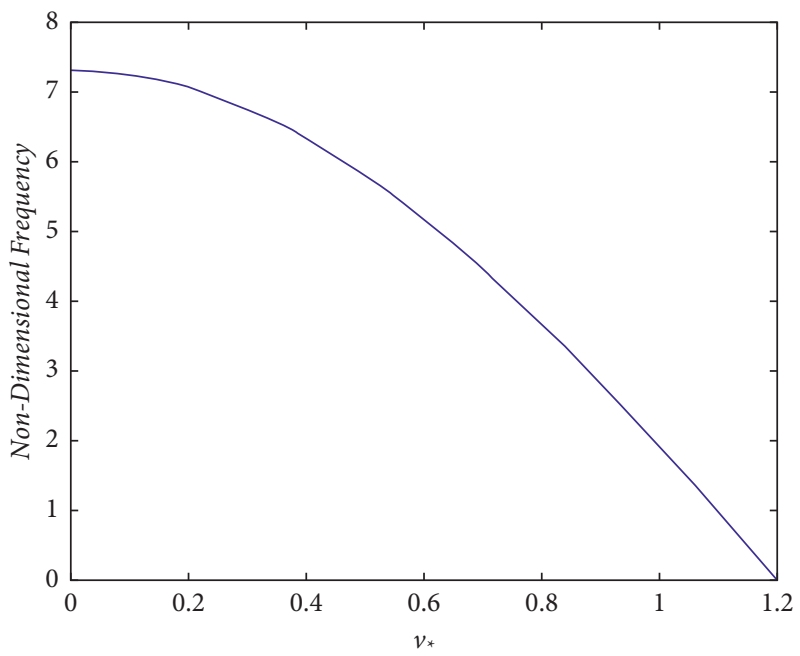

FIGURE 5: Nondimensional frequency vs. nondimensional axial speed.

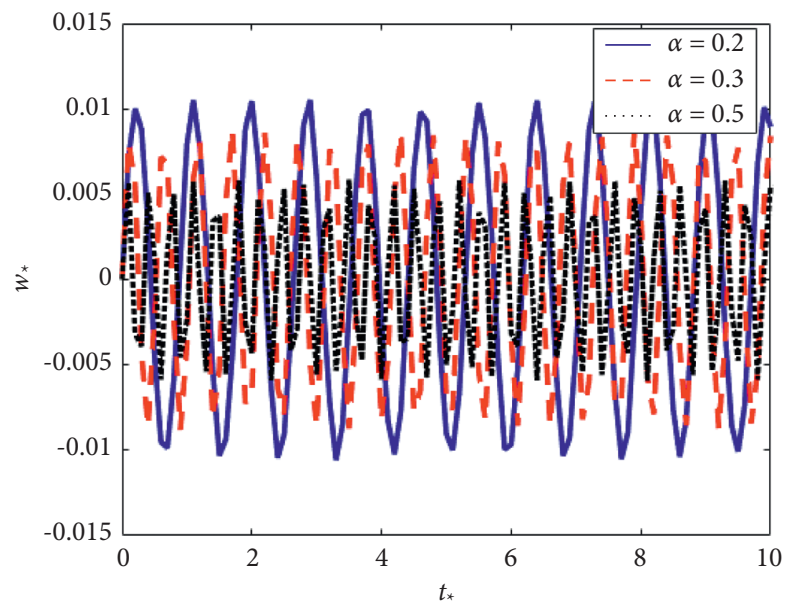

Figure 6: Transverse displacement comparison at different values of flexural rigidity $\left(x_{*}=0.5\right.$ and $\left.v_{*}=0.1\right)$.

opposite effect to damping on the nondimensional frequency and critical speed is observed in the case of stiffness of the foundation. The frequency of the beam increases from 7.3 to 8.8 , and the critical speed increases from 1.18 to 1.43 when the linear stiffness of the beam increases from 0.6 to 1.5 (corresponding to $800 \mathrm{~N} / \mathrm{m}$ and $6000 \mathrm{~N} / \mathrm{m}$, respectively).

A case of a forced vibration was also considered with external excitation force $f\left(x_{*}, t_{*}\right)=F \sin \left(\Omega t_{*}\right)$. The magnitude of the excitation force is "F," and the frequency of the excitation is $\Omega$. Frequency and displacement of the axially moving beam were measured under various excitation frequencies and are presented in Figure 12.

Figures 12(a)-12(c) show the frequency domain response of the axially moving beam. Starting with lower excitation frequency $(\Omega=1.0)$, frequency domain response, Figure 12(a) indicates that the fundamental frequency of the beam is higher than the excitation frequency $\left(\omega_{2}>\omega_{1}\right)$. As the excitation frequency is increased, fundamental frequency of the beam and the external excitation frequency match at " $\Omega=7.4$," and as a result, the response increases exponentially (Figure 12(d)). 


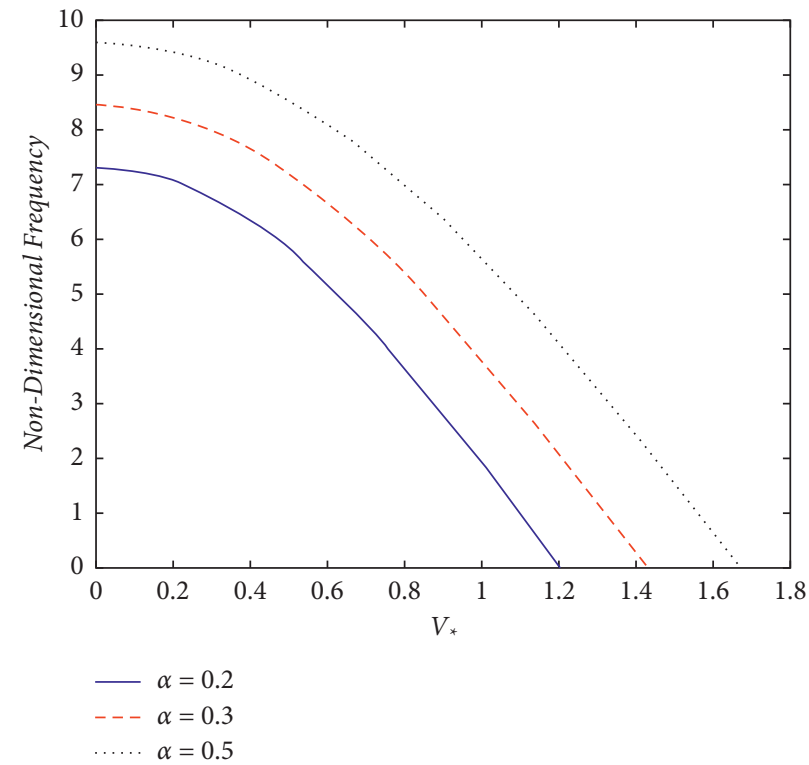

Figure 7: Comparison of nondimensional frequencies at different flexural rigidities.
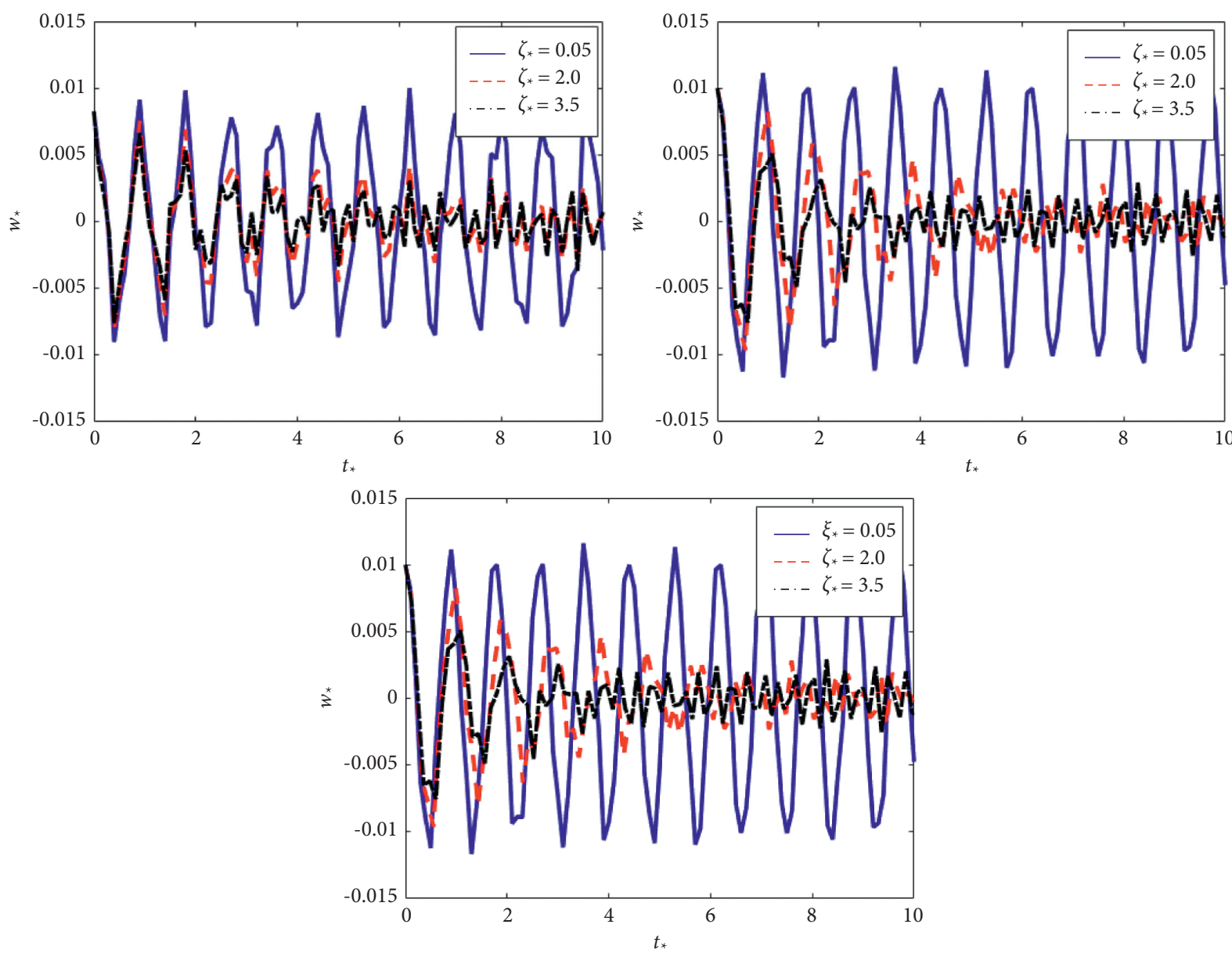

FiguRE 8: Transverse displacement comparison of the beam at different values of the damping factor " $\xi_{*}$." (a) $x_{*}=0.3$, (b) $x_{*}=0.5$, and (c) $x_{*}=0.7$. 

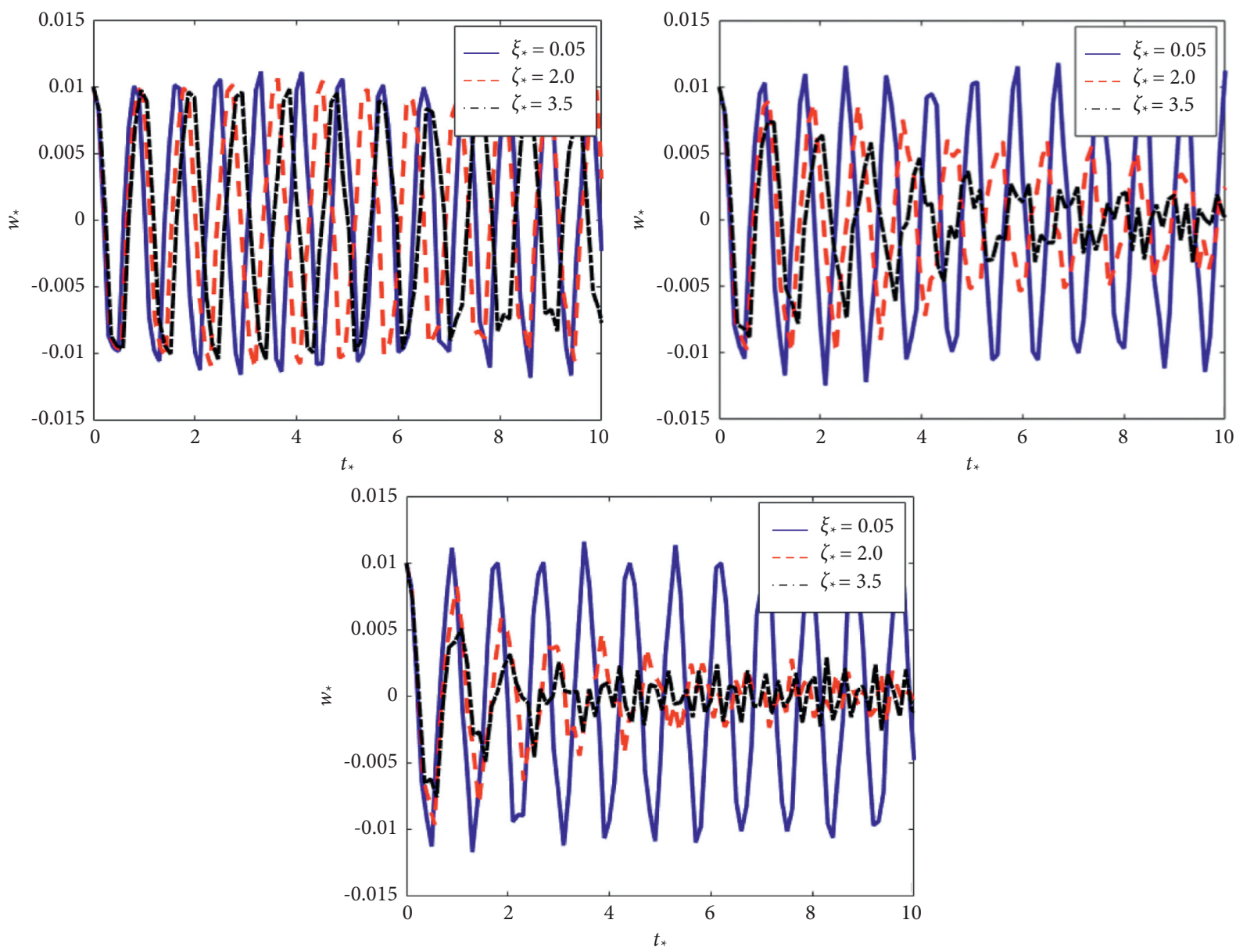

FiguRE 9: Transverse displacement comparison of the beam at different values of the damping factor " $\xi_{*}$ ” and at $x_{*}=0.5$ : (a) $v_{*}=0.1$, (b) $v_{*}=0.3$, and (c) $v_{*}=0.5$.
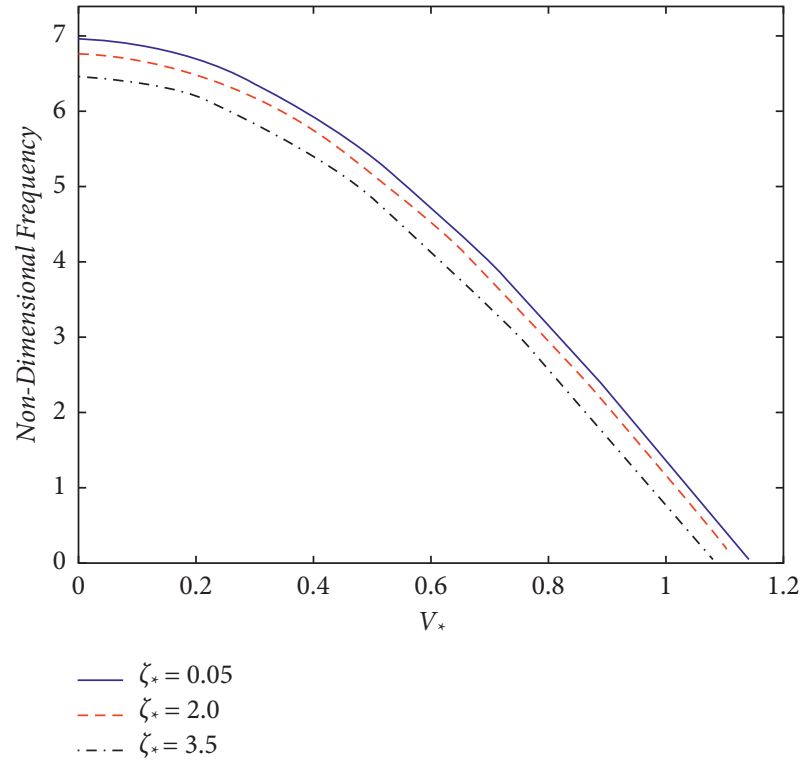

FIGURE 10: Comparison of frequencies at different damping factors $' \xi_{*}=0.05,2.0,3.5$. .'

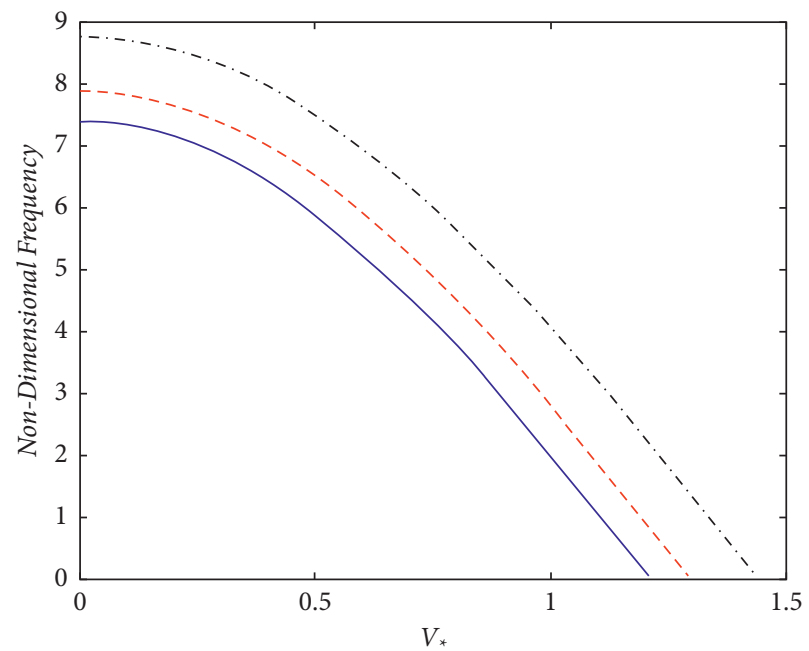

$$
\begin{aligned}
& -k_{1^{*}}=0.6 \\
& ---k_{1^{*}}=1.0 \\
& -\cdot-k_{1^{*}}=1.5
\end{aligned}
$$

FIgURE 11: Comparison of frequencies at different stiffnesses ' $k_{1 *}=0.6,1.0,1.5$. . 


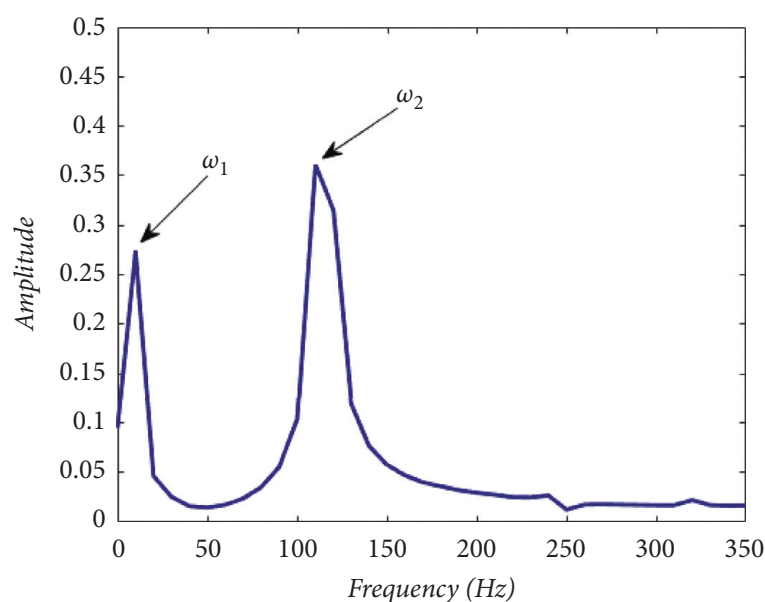

(a)

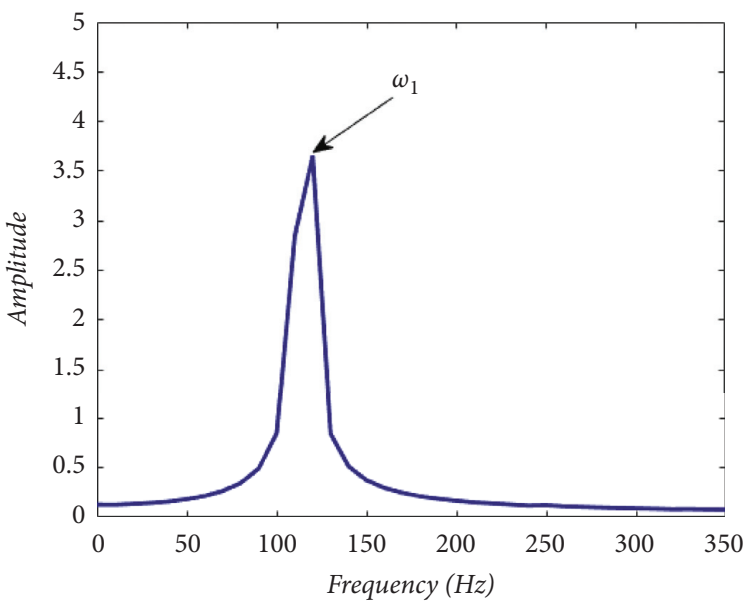

(c)

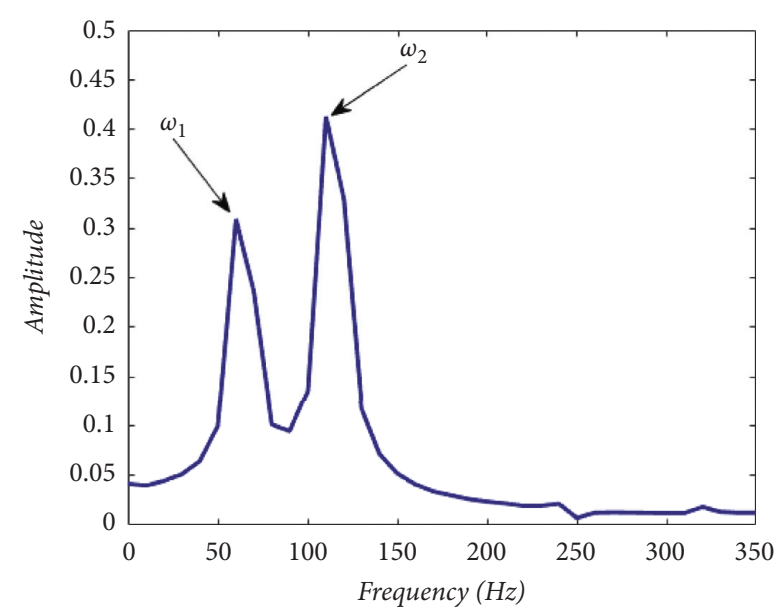

(b)

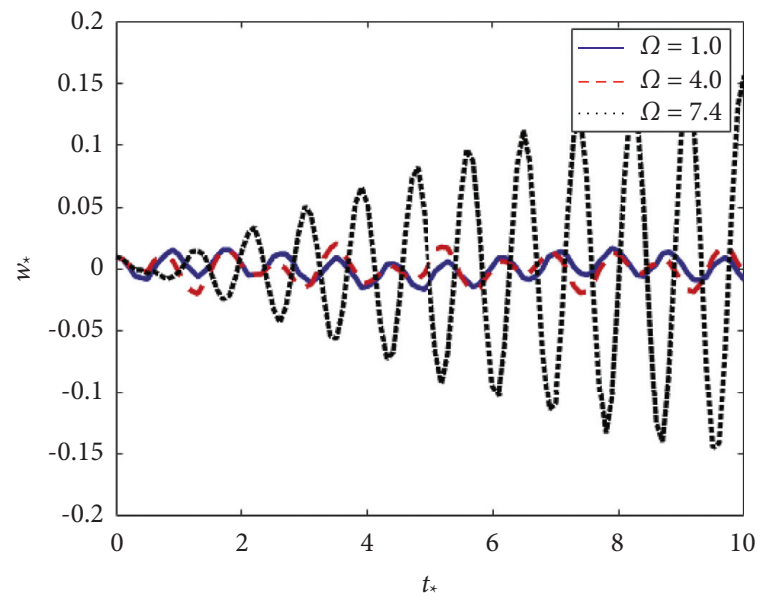

(d)

Figure 12: Frequency domain response at (a) $\Omega=1.0$, (b) $\Omega=4.0$, (c) $\Omega=7.4$, and (d) midspan displacement comparison at different values of nondimensional frequency " $\Omega$.".

\section{Conclusions}

In this study, transverse vibrations in axially traveling beam, supported by the viscoelastic intermediate foundation, was studied. Nonlinear equations of motion were derived using Hamilton's principle. The finite difference method coupled with the state-space approach was presented as an efficient solution technique. The effect of parameters, such as axial translation velocity, flexure rigidities of the beam, damping, and stiffness of the support on the transverse response amplitude and frequencies of the system in subcritical region, was investigated. The major findings of this study may be summarized as follows:

(i) In the absence of effective damping, the dimensionless fundamental frequency was observed to decrease with the increasing value of axial speed. Having the positive value of 7.3 for the case of stationary beam ultimately reaches to zero for an axial speed approaching a value of 1.18. Although, the fundamental frequency of the vibration is decreasing, the amplitude of vibration is unaffected. (ii) Higher value of flexure rigidity increases the internal damping (in terms of lower vibration amplitude) but at the cost of higher fundamental frequency. A decrease of $24 \%$ in the peak magnitude of transverse displacement is observed with increasing $\alpha$ from 0.2 to 0.3 and $47 \%$ decrease in the peak magnitude by increasing $\alpha$ from 0.3 to 0.5 . In contrast, increasing the flexural rigidity, nondimensional frequency, and critical speed of the beam increases from 7.3 to 9.8 and 1.18 to 1.65 , respectively.

(iii) With an increase in the damping of support, there is a visible reduction in the vibration amplitude. Interestingly, the vibration amplitude reduction is found to be more significant when the beam is moving with a higher axial speed. A significant reduction in the peak vibration magnitude is observed for the case of beam having $\xi_{*}=3.5$ and axial speed of $v_{*}=0.5$. Nondimensional frequency decreases from 7.3 to 6.4 , and critical speed decreases from 1.18 to 1.15 when the damping is increased from 0.05 to 3.5 . 
(iv) Higher value of the foundation stiffness results in the increase of both nondimensional frequencies as well as the critical speed of the beam. Critical speed increases from 1.18 to 1.43 , whereas the nondimensional frequency of the beam increases from 7.3 to 8.8 when the linear stiffness of the beam is increased from 0.6 to 1.5 .

\section{Abbreviations}

$\begin{array}{ll}\text { A: } & \text { Cross-sectional area of the beam } \\ v_{*}: & \text { Dimensionless axial speed } \\ \mathrm{E}: & \text { Modulus of elasticity of beam } \\ b\left(x_{*}\right): & \text { Initial transverse speed } \\ \mathrm{T}: & \text { Tension in beam } \\ \rho: & \text { Density of the beam } \\ v: & \text { Axial speed of beam } \\ \mathrm{L}: & \text { Beam length } \\ \xi: & \text { Foundation damping } \\ w: & \text { Transverse displacement } \\ k_{1}: & \text { Linear stiffness of foundation } \\ \alpha: & \text { Dimensionless flexural rigidity } \\ k_{2}: & \text { Nonlinear stiffness of foundation } \\ a\left(x_{*}\right): & \text { Initial transverse deflection. }\end{array}$

\section{Data Availability}

The underlying data supporting the results of this work are found within the article.

\section{Conflicts of Interest}

The authors have no conflicts of interest to disclose.

\section{Acknowledgments}

The authors appreciate and acknowledge the research support provided by the Deanship of Scientific Research, Imam Abdulrahman Bin Faisal University (IAU), for conducting this study.

\section{References}

[1] K. W. Wang and C. D. Mote Jr, "Vibration coupling analysis of band/wheel mechanical systems," Journal of Sound and Vibration, vol. 109, no. 2, pp. 237-258, 1986.

[2] K. Behdinan and B. Tabarrok, "Dynamics of flexible sliding beams-non-linear analysis part II: transient response," Journal of Sound and Vibration, vol. 208, 1997.

[3] P.-T. Pham and K.-S. Hong, "Dynamic models of axially moving systems: a review," Nonlinear Dynamics, vol. 100, no. 1, pp. 315-349, 2020.

[4] J. W. Lee, J. Y. Lee, and D. M. Lee, "Free vibration analysis of axially moving beams using the transfer matrix method," Journal of Mechanical Science and Technology, vol. 35, no. 4, pp. 1369-1376, 2021.

[5] C. H. Riedel and C. A. Tan, "Dynamic characteristics and mode localization of elastically constrained axially moving strings and beams," Journal of Sound and Vibration, vol. 215, 1998.
[6] B. Daraei, S. Shojaee, and S. Hamzehei-Javaran, "Analysis of stationary and axially moving beams considering functionally graded material using micropolar theory and Carrera unified formulation," Composite Structures, vol. 271, Article ID 114054, 2021.

[7] H. R. Öz and M. Pakdemirli, "Vibrations of an axially moving beam with time-dependent velocity," Journal of Sound and Vibration, vol. 227, 1999.

[8] F. Pellicano and F. Vestroni, "Nonlinear dynamics and bifurcations of an axially moving beam," $J$ Vib Acoust Trans ASME, vol. 122, 2000.

[9] F. Pellicano, A. Fregolent, A. Bertuzzi, and F. Vestroni, "Primary and parametric non-linear resonances of a power transmission belt: experimental and theoretical analysis," Journal of Sound and Vibration, vol. 244, 2001.

[10] L. Q. Chen, X. D. Yang, and C. J. Cheng, "Dynamic stability of an axially accelerating viscoelastic beam," European Journal of Mechanics-A: Solids, vol. 23, 2004.

[11] M. A. Hawwa, S. Ali, and D. E. Hardt, "Influence of roll-to-roll system's dynamics on axially moving web vibration," Journal of Vibroengineering, vol. 21, no. 3, pp. 556-569, 2019.

[12] H. Oh, U. Lee, and D. H. Park, "Dynamics of an axially moving Bernoulli-euler beam: spectral element modeling and analysis," KSME International Journal, vol. 18, 2004.

[13] S. Ali and M. A. Hawwa, "A parametric study on the dynamics of two-span roll-to-roll microcontact printing system," Sadhana-Academy Proceedings in Engineering Sciences, vol. 44, pp. 1-11, 2019.

[14] A. A. N. Al-Jawi, C. Pierre, and A. G. Ulsoy, "Vibration localization in dual-span, axially moving beams, Part I: formulation and results," Journal of Sound and Vibration, vol. 179, 1995.

[15] Y. Cheng, Y. Wu, and B.-Z. Guo, "Absolute boundary stabilization for an axially moving Kirchhoff beam," Automatica, vol. 129, Article ID 109667, 2021.

[16] S. Ali, M. A. Hawwa, and D. E. Hardt, "Vibration suppression of an axially moving web in a multi-span roll-to-roll microcontact printing system," Journal of Vibration Engineering and Technologies, vol. 8, 2020.

[17] M. Gaith and S. Müftü, "Transverse vibration of two axially moving beams connected by an elastic foundation," in Proceedings of the American Society of Mechanical Engineers, Dynamic Systems and Control Division (Publication) DSC, Orlando, FL, USA, November 2005.

[18] X. D. Yang, C. Lim, and K. Liew, "Vibration and stability of an axially moving beam on elastic foundation," Advances in Structural Engineering, vol. 13, 2010.

[19] H. Ding and L. Q. Chen, "Galerkin methods for natural frequencies of high-speed axially moving beams," Journal of Sound and Vibration, vol. 329, 2010.

[20] N. Liu, G. Yang, and B. Chen, "Transverse vibration analysis of an axially moving beam with lumped mass," J Vibroengineering, vol. 16, pp. 3209-3217, 2014.

[21] A. Moslemi, S. E. Khadem, M. Khazaee, and A. Davarpanah, "Nonlinear vibration and dynamic stability analysis of an axially moving beam with a nonlinear energy sink," Nonlinear Dynamics, vol. 104, no. 3, pp. 1955-1972, 2021.

[22] D. Karličić, M. Cajić, S. Paunović, and S. Adhikari, "Periodic response of a nonlinear axially moving beam with a nonlinear energy sink and piezoelectric attachment," International Journal of Mechanical Sciences, vol. 195, 2021.

[23] H. Norouzi and D. Younesian, "Chaotic vibrations of beams on nonlinear elastic foundations subjected to reciprocating loads," Mechanics Research Communications, vol. 69, 2015. 
[24] S. Mohammadzadeh and S. A. Mosayebi, "Dynamic analysis of axially beam on visco-elastic foundation with elastic supports under moving load," International Journal of Transportation Engineering, vol. 2, pp. 289-296, 2015.

[25] S. Kural and E. Özkaya, "Size-dependent vibrations of a micro beam conveying fluid and resting on an elastic foundation," JVC/Journal of Vibration and Control, vol. 23, 2017.

[26] H. Yan, Q. Ni, H. L. Dai et al., "Dynamics and stability of an extending beam attached to an axially moving base immersed in dense fluid," Journal of Sound and Vibration, vol. 383, 2016.

[27] F. F. Calim, "Free and forced vibration analysis of axially functionally graded Timoshenko beams on two-parameter viscoelastic foundation," Composites Part B: Engineering, vol. 103, 2016.

[28] Y.-Q. Tang, Y. Zhou, S. Liu, and S.-Y. Jiang, "Complex stability boundaries of axially moving beams with interdependent speed and tension," Applied Mathematical Modelling, vol. 89, pp. 208-224, 2021.

[29] A. Mirzabeigy and R. Madoliat, "La rge amplitude free vibration of axially loaded beams resting on variable elastic foundation," Alexandria Engineering Journal, vol. 55, 2016.

[30] A. Ghannadiasl, "Analytical study of dynamic response of railway on partial elastic foundation under travelling accelerating concentrated load," International Journal of Transportation Engineering, vol. 4, pp. 317-334, 2017.

[31] H. Zhang, J. Ma, H. Ding, and L. Chen, "Vibration of axially moving beam supported by viscoelastic foundation," Applied Mathematics and Mechanics, vol. 38, 2017.

[32] H. Ding, X. Tan, and E. H. Dowell, "Natural frequencies of a super-critical transporting Timoshenko beam," European Journal of Mechanics-A: Solids, vol. 66, pp. 79-93, 2017.

[33] X. Zhao, C. F. Wang, W. D. Zhu, Y. H. Li, and X. S. Wan, "Coupled thermoelastic nonlocal forced vibration of an axially moving micro/nano-beam," International Journal of Mechanical Sciences, vol. 206, 2021.

[34] N. Mohamed, M. A. Eltaher, S. A. Mohamed, and L. F. Seddek, "Numerical analysis of nonlinear free and forced vibrations of buckled curved beams resting on nonlinear elastic foundations," International Journal of Non-Linear Mechanics, vol. 101, 2018.

[35] C. An and J. Su, "Dynamic response of axially moving Timoshenko beams: integral transform solution," Applied Mathematics and Mechanics, vol. 35, no. 11, pp. 1421-1436, 2014.

[36] I. Esen, "Dynamic response of a functionally graded Timoshenko beam on two-parameter elastic foundations due to a variable velocity moving mass," International Journal of Mechanical Sciences, vol. 153-154, 2019.

[37] H. Ding, M. Zhu, and L. Chen, "Dynamic stiffness method for free vibration of an axially moving beam with generalized boundary conditions," Applied Mathematics and Mechanics, vol. 40, 2019.

[38] M. Shao, J. Wu, Y. Wang, and Q. Wu, "Nonlinear parametric vibration and chaotic behaviors of an axially accelerating moving membrane," Shock and Vibration, vol. 2019, Article ID 6294814, 11 pages, 2019. 